\title{
Three short studies from field studies in marine biology and oceanography
}

Dept. Integrative Biology, College of Biological Science, University of Guelph, Guelph, ON Canada. Faculty supervisor: Todd E. Gillis. For information regarding ZOO*4300, please email: tgillis@uoguelph.ca.

\section{Overview}

Z00*4300 (Marine Biology and Oceanography) is a senior-level field course offered by the Department of Integrative Biology at the University of Guelph. This two-week course is held at the Huntsman Marine Science Centre in St. Andrew's New Brunswick, Canada. Students enrolled in the course study various aspects of the ecology, behaviour, physiology, biochemistry and genetics of marine organisms using a variety of oceanographic techniques. The course also includes group exercises to study various intertidal and sub-tidal environments as well as boat cruises to collect plankton, benthic invertebrates, marine fish, and to observe marine mammals. The course provides excellent opportunities for students to familiarize themselves with state-of-the-art techniques involved in various branches of marine biology and oceanography and conduct an individual research project. This feature highlights three individual research projects by University of Guelph students. More information about the field course in marine biology and oceanography is accessible at the following link: http://www.uoguelph.ca/ib/undergrad/fieldcourses marine.shtml.

\section{The effect of abiotic and biotic factors on the size distribution and abundance of the blue mussel (Mytilus edulis) in tide pools on a rocky intertidal shore}

Melanie Barry

For correspondence please email: mel.barry@rogers.com.

\section{Abstract}

Tide pools display unique qualities such as size, shading, and the interval between tidal flushing. These variations lead to differences in environmental factors such as temperature, dissolved oxygen (DO), salinity, wave exposure, and $\mathrm{pH}$, as well as differences in biological factors such as macrophyte coverage. The blue mussel, Mytilus edulis, is commonly found in tide pools and plays a key role in tide pool communities as it is a food source for many organisms. In this study, the size distribution and abundance of the blue mussel was investigated. Measurements were taken in 10 tide pools, separated into three different sites in a rocky intertidal zone in New Brunswick, Canada. The sites were located at various heights in the intertidal zone at Green's Point, and experienced varying degrees of wave exposure. The abundance of mussels was quantified by averaging the number of mussels found in quadrats placed in each pool while the size of the mussels was determined by measuring the shell length (SL). The environmental and biological factors previously described were measured in each of the tide pools. Regression analyses revealed a significant increase in muscle size with increased DO levels, as well as a significant increase in shell thickness with increasing shell length. It was also determined that both the abundance and size of the mussels differed significantly between the three study sites.

Keywords: Mytilus edulis; tide pools characteristics (abiotic and biotic); size distribution; abundance 


\section{Introduction}

The blue mussel, Mytilus edulis, is a common inhabitant of tide pools found in the intertidal zones of rocky shores (Hunt \& Scheibling, 1995). Organisms that inhabit tide pools and are submerged for the entire tidal cycle and are subject to smaller fluctuations in physical factors compared to those found on the exposed surface of the rocky intertidal zone. Fluctuations in these tide pools are also smaller than those in tide pools that empty during low tide (Metaxas \& Scheibling, 1993). As a result, the distribution pattern of various organisms becomes apparent as some species such as some fucoids and barnacles have a tendency to inhabit emergent rock habitats while others such as algae, focus, and gastropods are more likely to assemble in tide pools (Metaxas \& Scheibling, 1993). At low tide, these rocky pools can provide shelter and protection to organisms from stressful environmental conditions that could otherwise result in desiccation or freezing (Metaxas \& Scheibling, 1993). They can also serve as protection from the force of incoming waves since the action of breaking waves threatens to dislodge organisms that are found on exposed rocky shores (Hunt \& Scheibling, 2001). Metaxas and Scheibling (1993) describe how each tide pool is unique as a result of varying characteristics including: depth, volume, orientation, shading and the interval between tidal flushing. The change in water height that allows for the renewal of water in tide pools, described as the tidal cycle, acts to regulate these characteristics. Therefore, there is less variation in low tide pools compared to those that are higher on the shore (Metaxas \& Scheibling, 1993).

In this study, the effect of a number of abiotic and biotic factors related to tide pools on the size distribution and abundance of the blue mussel, $M$. edulis, were examined. Tide pools at three different sites at Green's Point, New Brunswick were studied. The abiotic characteristics that were investigated included: the size of the pool (volume), water temperature, sunlight exposure, dissolved oxygen saturation, wave exposure, and intertidal height. The percentage of algae coverage is a biotic characteristic that was also considered. With regards to active habitat selection, mussel larvae tend to be sensitive to both abiotic and biotic factors, which play a role in determining where they will settle (Hunt \& Scheibling, 1996). It was hypothesized that both the abundance and size distribution of these organisms would vary in tide pools of different sizes with variations in these characteristics. The degree to which each factor affected the size and abundance of mussels was also expected to differ. For example, due to the large variation in dissolved oxygen levels in tide pools (McMahon, 1998), DO was expected to have more of an effect than other less variable factors.

While high wave exposure has the potential to dislodge organisms, some wave exposure is necessary as it affects the supply of food to mussels and other suspension feeders, as well as delivers nutrients to macroalgae and larvae to the substrate (Hunt \& Scheibling, 2001). Tide pools that are found in areas with adequate wave exposure are subsequently expected to contain a higher density of larger mussels.

Mussels play a key role in intertidal systems and their presence has been shown to increase the primary productivity in a tide pool habitat. In previous studies it was determined that algae can serve as a settlement site for mussel larvae and the addition of mussels to pools has also resulted in an increase in algae (Hunt \& Scheibling, 1996; Pfister, 2007). Algae can also act as a canopy, providing shade to pools, which keeps them cool and dark and can protect inhabitants from visual predators (Dethier, 1984). Based on these findings, more mussels are predicted to be found in tide pools with a higher percentage of macrophyte coverage. Biological and physical processes such as shifts in the balance of respiration and photosynthesis, varying temperatures, and the tidal cycle can lead to large variations in the oxygen saturation of tide pools (McMahon, 1988; Metaxas \& Scheibling, 1993). As a result of photosynthetic processes, pools that have more algae are also expected to have higher levels of dissolved oxygen and, accordingly, a larger number of larger mussels.

The temperature of a tide pool is dependent on factors including the height of the pool, the degree of wave exposure, the degree of shading, and the volume (Metaxas \& Scheibling, 1993). More invertebrate and plant species have been found in deeper tide pools as deeper pools present fewer stresses to organisms because of the associated colder temperatures (Dethier, 1984; Metaxas \& Scheibling, 1993). It is predicted that deeper pools with colder temperatures and consequently higher levels of dissolved oxygen will house a higher density of large mussels. These tide pools are likely to be found in the lower portion of the intertidal zone where the interval between tidal flushing is shorter.

Studying what affects the size distribution of mussels is important as they are a critical member of tide pool communities. Besides speeding up the production and breakdown of organic matter, the blue mussel is an important food source for many organisms (Dankers \& Zuidema, 1995). Variations in the abundance of this species can result in a trophic cascade where other organisms are subject to an increase or decrease in predation (Trussel, Ewanchuk, Bertness, \& Silliman, 2004). As a dominant filter feeder, the abundance of the blue mussel influences the diversity of the entire community while competing for space and food (Enderlein \& Wahl, 2004; Quinn, Boudreau, \& Hamilton, 2012). Therefore, studying what factors play a role in determining the size distribution and abundance of this species has the potential to provide information regarding the community structure in a tide pool habitat. 


\section{Three short studies from field studies in marine biology and oceanography}

\section{Methods}

\section{Experimental procedure}

Ten tide pools in the rocky intertidal zone of St. Andrews, New Brunswick were examined. The pools were chosen at random at various heights of the rocky intertidal zone at Green's Point. A range of differently-sized pools were chosen with a minimum depth of approximately $2.5 \mathrm{~cm}$. Dethier (1984) describes how those that are less than $2.5 \mathrm{~cm}$ deep frequently dry up, which results in exposure to drastically different environmental conditions. The pools were grouped into three separate "sites" in the intertidal zone. These sites were at various heights in the intertidal zone, and subject to varying degrees of wave exposure. The tide pools were grouped into sites based on their height and location in the intertidal zone. Study site one was located at the highest point of the intertidal zone where wave exposure was predicted to be minimal. Study site two was lower in the intertidal zone where the terrain was extremely rocky and coated in the macrophyte Fucus vesiculosus. Finally, study site three was in a location where water flow was constant and fast because it was in a small channel that leads into Passamaquoddy Bay.

A meter stick and tape measure were used to measure the depth and dimensions of each tide pool. In order to calculate the area, a meter stick was placed in each pool as a reference and then a picture was taken. The area was then measured by tracing the perimeter of the pool in ImageJ. The temperature and dissolved oxygen (DO) content of each pool was measured using an AYSI Model 55 oxygen meter. A HOBO Pendant ${ }^{\circledR}$ Temperature/Light Data Logger (Onset Computer Corporation) was placed in each pool before data collection began and then retrieved at the end of the sampling period. The temperature data recorded by these devices was used to determine the change in temperature in each tide pool. The salinity of each pool was measured using a hand held salinity refractometer and the $\mathrm{pH}$ was measured using a portable $\mathrm{pH}$ meter (H1 98127 HANNA).

A force dynamometer was used to quantify the wave exposure that each tide pool is subjected to. Three dynamometers similar to those described by Bell and Denny (1994) were constructed and placed at each of the three described "sites" at Green's Point. The devices were constructed from $30 \mathrm{cc}$ syringe barrels. A window was first cut into the side of the barrels to allow access to the inside of the tube. A piece of fishing line was threaded through the rubber stopper and then through the hub of the syringe. A wiffle ball was tied to the fishing line on the outside of the barrel. The other end of the line was tied to a spring which was then housed inside the barrel. The spring was secured to the top of the syringe using the plunger of a smaller syringe and a hot glue gun. A short chain was then tied to the top of the syringe to provide a way to attach the device to the ground via cement screws. When exposed to wave action the wiffle ball was expected to get tugged on, causing the spring to push the rubber stopper through the barrel where it would stay and act as an indicator of wave forces. In order to quantify the wave exposure, pre-calibrated dynamometers (ME Spring Scales) were used to determine the relationship between spring extension and force.

Similar to studies by Hunt and Scheibling (1996), three quadrats were used and the number of mussels in each were counted and averaged between the quadrats to determine the average abundance in each pool. The quadrats were also used to estimate the percent coverage of algae in each pool, which is comparable to the methods in a study on disturbance and recovery in tide pools by Dethier (1984). The quadrats used in pools $1,2,3,4,5,6$, and 10 measured $50 \times 50 \mathrm{~cm}$ as mussels that inhabit tide pools are commonly found in centimeter-scale patches (Hunt \& Scheibling, 1996). In pools 7,8 and 9 , the coverage of mussels was very large and $10 \mathrm{x}$ $10 \mathrm{~cm}$ quadrats were used instead.

In order to determine the size distribution, Vernier calipers were used to measure the shell length (SL) of the mussels in each quadrat (Hunt \& Scheibling, 1996; Hunt \& Scheibling, 2001; Dethier, 1984). With the purpose of determining the shell thickness, five mussels were collected from each pool and brought back to the lab for analysis. The thickness was measured with Vernier calipers in the same location of each shell and was then divided by the shell length in order to standardize the measurements.

The location of each pool was marked with a Garmin Global Positioning System (GPS) (Oregon ${ }^{\mathrm{TM}} 450$ model) so that they could be found again at a later date. Data was collected at low tide each day between August $13^{\text {th }}$ and $16^{\text {th }}$, 2012.

\section{Statistical analysis}

The relative abundance of blue mussels in each pool was determined after taking the area of the quadrat and the tide pool into account. The average shell length was also calculated for each tide pool. A series of linear regression analyses were then performed in Microsoft Excel 2007. Regressions were conducted between both the shell length and the abundance of mussels in each pool and compared with each of measured parameters (pool volume, temperature, change in temperature, $\mathrm{DO}$, salinity, $\mathrm{pH}$, and the percent of macrophyte coverage). The shell lengths from each pool were grouped according to the site they were found in. An ANOVA and Tukey's Post Hoc test were then performed to determine if there was a difference in shell length between sites. The same was then carried out for the abundance of mussels at each site.

\section{Results and Discussion}

Results from the ANOVA identified a significant difference in the abundance of mussels between the three study sites. Tukey's Post Hoc test showed that the abundance was significantly higher at site three compared to site one, and higher at site three compared to site two $(\mathrm{p}<0.05$; Figure 1). There was no significant difference in abundance 


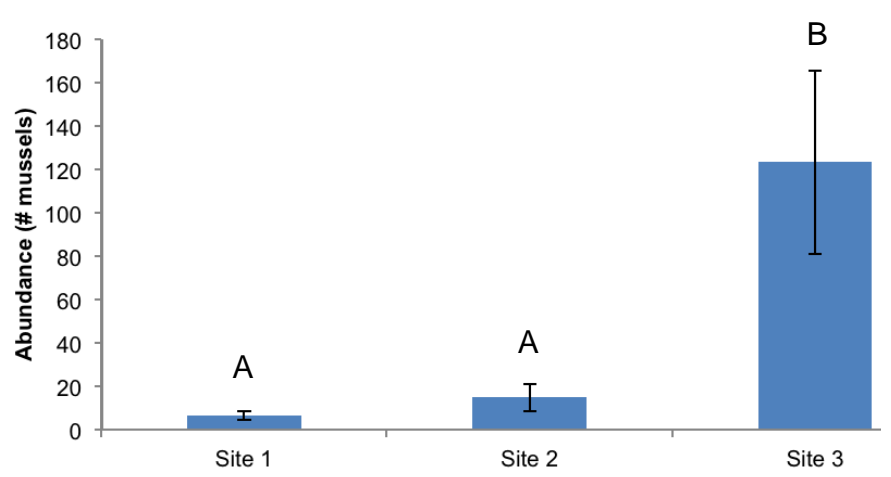

Figure 1. Differences in the abundance of blue mussels (Mytilus edulis) in three tide pools at Green's Point, NB is displayed. Bars indicated by a different letter are statistically different $(p<0.05)$. Error bars represent the standard error.

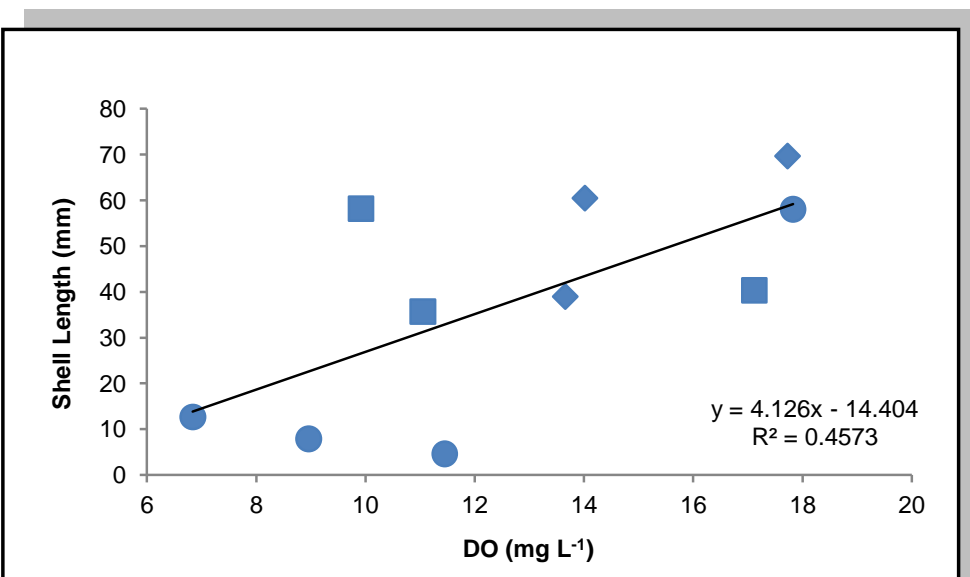

Figure 2. Shell length of blue mussels (Mytilus edulis) increases with dissolved oxygen (DO) $(p=0.0313 ; t=2.596 ; d f=9)$. Squares represent tide pools from site one, diamonds represent tide pools from site two, and circles represent tide pools from site three.

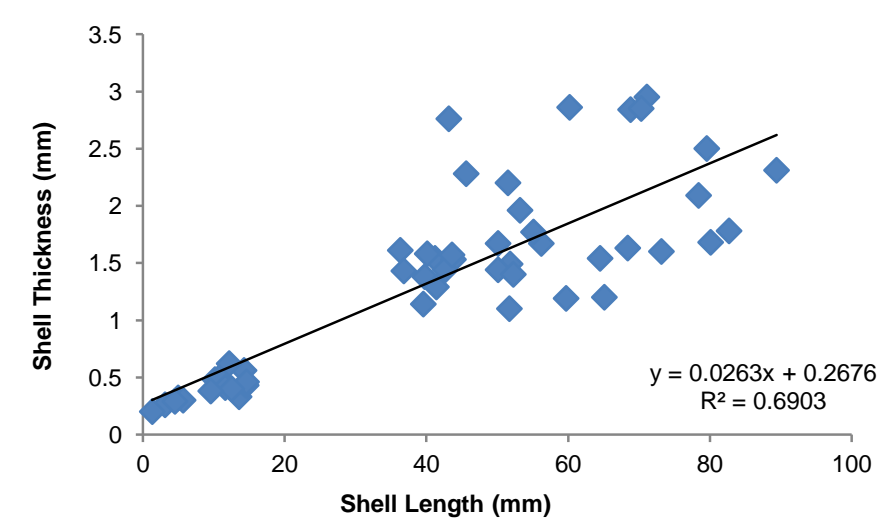

Figure 3: The thickness of blue mussel (Mytilus edulis) shell increases with shell length. $(p=8.290 E-14 ; t=10.34 ; d f=9)$.

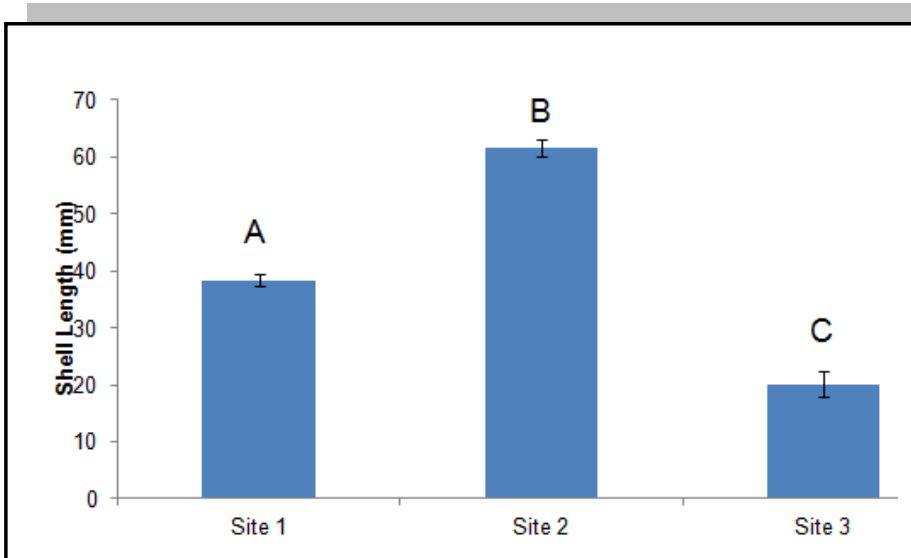

Figure 4. The average shell length different between all three locations at Point, NB is displayed. Bars indicated by a different letter are statistically different $(p<0.05)$. Error bars represent the standard error. 


\section{Three short studies from field studies in marine biology and oceanography}

between sites one and two. Differences in abundance at the sites may have been related to variation in wave exposure.

The results obtained from the wave force dynamometers revealed that wave forces at site one were less than $0.1 \mathrm{~N}$, were $2.5 \mathrm{~N}$ at site two, and greater than $1.0 \mathrm{~N}$ at site three. These values are difficult to compare since the springs appeared to have different tensions, and in some cases the spring had extended the full length of the case, meaning that the wave forces may have exceeded the measuring capability of the dynamometer (site three) or did not move (site one). While the results from the force dynamometers were not precise enough to allow for comparisons between quantitative exposure records, observations were made regarding the flow at each site. Site three experienced a constant fast flow of water as it moved into the Passamaquoddy Bay. This is where the largest abundance of mussels was found. This is also where the smallest, and likely the youngest mussels were measured.

Relating these observations to wave exposure, it is likely that mussel larvae were deposited at three due to the constant flow of water through the channel. As described by Hunt and Scheibling (1996), mussel larvae settlement is based on both passive and active processes. Active processes relate to behavioural habitat selection while hydrodynamics constitute passive settlement. The amount of larvae deposited in an area increases with an increased water flow (Hunt \& Scheibling, 1996; Westerbom \& Jattu, 2006). Larvae are deposited at large spatial scales (Hunt \& Scheibling, 1996), which is consistent with the extensive coverage of small mussels found at site three. It is possible that the wave exposure at this site is optimal, being constant enough to deliver larvae as well as provide food for sessile organisms such as the blue mussel. As described by Westerbom and Jattu (2006) and Hunt and Scheibling (2001), there is an equilibrium between wave action that could potentially increase the risk of dislodgement and waves that provide an adequate supply of nutrients as well as larvae to the area. Further experimentation regarding the wave exposure at each of these sites is necessary to better compare the relative water forces. There was no significant linear relationship between the relative abundance of blue mussels and any of the measured parameters.

There was a significant linear relationship identified between increasing dissolved oxygen in the tide pools and increasing shell length of the mussels $(p<0.05 ; t=2.596$; Figure 2). For every $1 \mathrm{mg} \mathrm{L}^{-1}$ increase in dissolved oxygen, a $4.13 \mathrm{~mm}$ increase in shell length was recorded in the mussels. It was expected that dissolved oxygen would have an effect based on the extreme variation that it presents in tide pools (McMahon, 1998). In a study by Wang, $\mathrm{Hu}$, Wong, Cheung, and Shin (2011), it was determined that certain growth parameters (including shell length) in the green-lipped mussel (Perna viridis) decreased under reduced DO concentrations and salinities. While the salinity did not appear to have an effect in the current study, a similar trend was identified with regards to DO. Nielson (2001) describes the relationship between increased photosynthesis from macrophytes and increased DO. There were no significant trends identified with regards to macrophyte coverage in the current study, but this could be due to possible inconsistencies in percent coverage estimation. A more quantitative approach to measuring macrophyte coverage may lead to more significant results. None of the factors that were measured had a significant effect on the abundance of this species.

A significant linear relationship was also detected between increasing shell thickness with increasing shell length $(\mathrm{p}<0.05 ; \mathrm{t}=10.34$; Figure 3). There was no linear relationship between the shell length and any of the other factors. The thickness increased by approximately $0.026 \mathrm{~mm}$ with every $1 \mathrm{~mm}$ increase in shell length. Again, this may be related to wave exposure. Results from the ANOVA revealed a significant difference in shell length between the three study sites. Tukey's Post Hoc test showed that the shell length of the mussels was significantly longer at site two compared to site one, higher at site one compared to site three, and higher at site two compared to site three $(\mathrm{p}<0.05$; Figure 4).The largest mussels were found at site two where the wave forces were measured to be $2.5 \mathrm{~N}$. While this is difficult to compare with site three where the wave forces exceeded the measuring capabilities of the dynamometer $(>1.0 \mathrm{~N})$, it was higher than the forces at site one $(<0.1 \mathrm{~N})$. A study by Akester and Martel (2000) on the bay mussel (M. trossulus) revealed that mussel shells were significantly thicker in an area of high wave exposure compared to a sheltered area. It is possible that the wave action at site two was too strong for larval settlement, while larger mussels with thicker shells were capable of surviving. Akester and Martel (2000) describe how thicker shells are necessary in areas of high wave exposure in order to endure erosion from the waves.

The results from this study may help shape a better understanding of the community structure in tide pools. The size of blue mussels appears to be associated with the dissolved oxygen levels in the pools and further research could focus on whether this trend is consistent with other tide pool organisms. Also, experimental studies could determine the minimum levels of dissolved oxygen that are required for growth, as the decreasing oxygen levels associated with global warming and eutrophication may be detrimental to blue mussel populations. In the water column, large nutrient inputs can lead to the development of large amounts of organic detritus and significant changes in dissolved oxygen (Alvera-Azcárate, Ferreira, \& Nunes, 2002). Stramma, Johnson, Sprintall, and Mohrholz (2008) describe how the increasing water temperatures associated with global warming are also linked to a decrease in oxygen levels. The degree to which eutrophication and global warming affect dissolved oxygen levels in tide pools requires further research, as these processes both have potential effects on the growth and survival of blue mussels. 


\section{References}

Akester, R.J., \& Martel, A.L. (2000). Shell shape, dysodont tooth morphology, and hinge-ligament thickness in the bay mussel Mytilus trossulus correlate with wave exposure. Canadian Journal of Zoology, 78(2), 240-253.

Alvera-Azcárate, A., Ferreira, J.G., \& Nunes, J.P. (2003). Modelling eutrophication in mesotidal and macrotidal estuaries: The role of intertidal seaweeds. Estuarine, Coastal and Shelf Science, 57, 715-724.

Dankers, N., \& Zuidema, D.R. (1995). The role of the mussel (Mytilus edulis L.) and mussel culture in the Dutch Wadden Sea. Estuaries, 18(1A), 71-80.

Dethier, M.N. (1984). Disturbance and recovery in intertidal pools: Maintenance of mosaic patterns. Ecological Monographs, 54(1), 99-118.

Enderlein, P., \& Wahl, M. (2004). Dominance of blue mussels versus consumer-mediated enhancement of benthic diversity. Journal of Sea Research, 51, 145-155.

Hunt, H.L., \& Scheibling, R.E. (1995). Structure and dynamics of mussel patches in tide-pools on a rocky shore in Nova Scotia, Canada. Marine Ecology Progress Series, 124, 105-115.

Hunt, H.L., \& Scheibling, R.E. (1996). Physical and biological factors influencing mussel (Mytilus trossulus, $M$. edulis) settlement on a wave-exposed rocky shore. Marine Ecology Progress Series, 142, 135-145.

Hunt, H.L., \& Scheibling, R.E. (2001). Predicting wave dislodgement of mussels: variation in attachment strength with body size, habitat and season. Marine Ecology Progress Series, 213, 157-164.
McMahon, B.R. (1988). Physiological responses to oxygen depletion in intertidal animals. American Zoologist, 28, 39-53.

Metaxas, A., \& Scheibling, R.E. (1993). Community structure and organization of tide pools. Marine Ecology Progress Series, 98, 187-198.

Pfister, C.A. (2007). Intertidal invertebrates locally enhance primary production. Ecology, 88(7), 1647-1653.

Quinn, B.K., Boudreau, M.R., \& Hamilton, D.J. (2012). Inter- and intraspecific interactions among green crabs (Carcinus maenas) and whelks (Nucella lapillus) foraging on blue mussels (Mytilus edulis). Journal of Experimental Marine Biology and Ecology, 412, 117-125.

Stramma, L., Johnson, G.C., Sprintall, J., \& Mohrholz, V. (2008). Expanding oxygen-minimum zones in the tropical oceans. Science, 320, 655-657.

Trussel, G.C., Ewanchuk, P.J., Bertness, M.D., \& Silliman, B.R. (2004). Trophic cascades in rocky shore tide pools: distinguishing lethal and nonlethal effects. Oecologia, 139, 427-432.

Wang, Y., Hu, M., Wong, W.H., Cheung, S.G., \& Shin, P.K.S. (2011). Combined effects of dissolved oxygen and salinity on growth and body composition of juvenile greenlipped mussel (Perna viridis). Journal of Shellfish Research, 30(3), 851-857.

Westerbom, M., \& Jattu, S. (2006). Effects of wave exposure on the sublittoral distribution of blue mussels Mytilus edulis in a heterogeneous archipelago. Marine Ecology Progress Series, 306, 191-200. 


\title{
2. Effects of salinity on the fertilization success and early larval development of the sand dollar Echinarachnius parma
}

\author{
Shannon Ferraro \\ For correspondence please email: shannon.ferraro@live.com.
}

Abstract

Global warming is a phenomenon affecting the entire planet, including the marine environment. Increased global temperatures will lead to freshwater influx due to polar ice melt. Marine animals that live near shore or in shallow waters may endure this change sooner than those in other oceanic zones. In this study, the effects of salinities ranging from 20 45 ppt on the fertilization success and early development were examined in the sand dollar Echinarachnius parma. It was found that fertilization success decreased by $\mathbf{2 0 - 9 5 \%}$ as salinity deviated from the control. It was also found that cleavage was non-existent at 20 and 45 ppt. Finally, it was observed that the morphology of the fertilized embryos was severely affected at the extreme high and low salinities. The results of this study are consistent with existing literature, and suggest that $E$. parma may suffer drastic population decline should a substantial divergence from normal oceanic salinities occur.

Keywords: Echinarachnius parma; fertilization; development; salinity; climate change

\section{Introduction}

It is predicted that increased global temperatures will cause polar ice melt and increased precipitation (Raper \& Braithwaite, 2006; Hanna et al., 2008). Together these phenomena will contribute to changes in oceanic chemistry, including salinity (Myers, Akenhead, \& Drinkwater, 1990; Cattle \& Crossley, 1995; Rignot \& Jacobs, 2002). Lower salinities are also more commonly observed in waters of higher temperatures, such as in shallow water or estuaries (Geyer, 1997; Chen, 2012) As global climate change continues, these areas may experience greater increases in freshwater run-off, and consequently greater declines in salinity. Studies have shown that the reproductive success of marine invertebrates that utilize external fertilization may experience detrimental effects in these areas when exposed to low salinity. Such species include the polychaetes Hediste japonica and $H$. diadroma, which have been found to be reproductively unsuccessful in salinities below 10 ppt (Tosuji \& Sato, 2006). A study by Ushakova and Sarantchova (2004) also found low salinity intolerance in the estuarine polychaete Nereis virens, which showed a lower threshold of approximately $22 \mathrm{ppt}$.

Although there have been several studies showing the effect of low salinity on developmental success of echinoderms, few experiments have been conducted to examine the effects of low salinity on fertilization success, and even fewer regarding high salinity. Echinoderms are ideal organisms for study due to their sensitivity to water chemistry and their rapidly-forming and easily recognized fertilization envelope (Vellutini \& Migotto, 2010). E. parma was an ideal specimen for this experiment due to its abundance in shallow water environments.

The purpose of this study is to investigate the effect of salinity on fertilization success and early larval development of Echinarachnius parma. Treatment salinity values were selected based on previous studies regarding the lower threshold for echinoderm fertilization (18-24 ppt) (Allen \& Pechenik, 2010; Bekova, Zhuravel, \& Khristoforva, 2004; Kashenko, 2006; Kashenko, 2007) and the ambient salinity from the collection site (33 ppt). It has been observed by Binyon (1966) that some species of adult echinoderms occur in environments up to $46 \mathrm{ppt}$. The current study also included a treatment in this salinity range to examine the possibility of E. parma occurring in a hypersaline environment. By observing the percentage of zygotes formed in five separate solutions each of different salinities, this study tested the hypothesis that fertilization in E. parma has become adapted to function optimally at the ambient salinity of 33 ppt over evolutionary time. This hypothesis predicts that increases or decreases in salinity should have detrimental effects on fertilization success. Any zygotes which are able to form in extreme salinities are not expected to demonstrate successful development.

\section{Methods}

\section{Experimental procedure}

Five male and five female E. parma were used in each trial of the experiment. These animals were collected from the lower intertidal zone at Bar Road,St. Andrews, New Brunswick, Canada. The specimens were maintained at the Huntsman Marine Science Center Laboratory (St. Andrew's, $\mathrm{NB}$ ) in a flow-through aquarium containing local seawater at $15^{\circ} \mathrm{C}$. Release of gametes was induced by injection of $1 \mathrm{~mL}$ of $0.5 \mathrm{M} \mathrm{KCl}$ into the mouth of the animal, as per Allen and Pechenik (2010). The specimens were then placed in $400 \mathrm{~mL}$ glass finger bowls with $100 \mathrm{~mL}$ of ambient seawater. Gametes were collected from the gonopore using a $14.6 \mathrm{~cm}$ 
Pasteur pipette. Sperm were held in a $50 \mathrm{~mL}$ beaker and kept on ice. Once sperm was collected from each male specimen, a $20 \mu \mathrm{L}$ sperm sample was added to $100 \mathrm{~mL}$ of seawater in a $250 \mathrm{~mL}$ beaker and maintained at $15^{\circ} \mathrm{C}$. Eggs were held in a $250 \mathrm{~mL}$ beaker with $50 \mathrm{~mL}$ of seawater maintained at $15^{\circ} \mathrm{C}$. The eggs were gently stirred to ensure even distribution throughout the beaker, and a $1 \mathrm{~mL}$ sample was taken for each treatment of $15^{\circ} \mathrm{C}$ saltwater at 20, 25, 33, 40, and $45 \mathrm{ppt}$ salinity with $33 \mathrm{ppt}$ being ambient salinity and acting as the control treatment (Instant Ocean Sea Salt). Salinity was measured using a hand held salinity refractometer (Vista, model A366ATC). Eggs were incubated in each treatment for fifteen minutes before the addition of $1 \mathrm{~mL}$ of diluted sperm to each treatment. Thirty minutes after the addition of the sperm, $250 \mu \mathrm{L}$ samples were taken from each treatment and were examined under a compound microscope. Percentage of fertilized eggs was counted as the number of eggs which had formed a fertilization envelope out of 100 eggs. Five trials of each treatment were conducted, from which the mean percentage of fertilization success was calculated.

An additional $250 \mu \mathrm{L}$ sample was taken from each treatment after three hours to examine degree of cleavage. Percentage of eggs cleaved was calculated by the number of zygotes that exhibited cleavage out of 100 fertilized eggs. The mean percentage of cleavage success was calculated using five trials of each treatment.

A further $250 \mu \mathrm{L}$ sample was taken from each treatment and was examined after approximately fifteen hours to allow further development to occur. Degree of embryonic development in each treatment was assessed by visual observation. Three trials of each treatment were calculated to ensure accuracy. Images of developmental stages were obtained using a digital microscope camera and ToupView version 3.2 software.

\section{Data analysis}

Data is expressed as mean \pm s.e.m. A one-way ANOVA was conducted to test for significant differences across treatments. When significance was found, a Tukey post-hoc test was used to compare individual treatments. Significance was assumed at $\mathrm{p}<0.05$. All statistical analyses were carried out using $\mathrm{R}$ version 2.12.1.

\section{Results and Discussion}

As salinity deviated from the control, fertilization success followed a negative trend (Figure 1). At ambient salinity (33 ppt), the mean percent fertilization was $84.3 \pm 3.1 \%$. At $25 \mathrm{ppt}$, this figure dropped to $68.2 \pm 1.8 \%$, although this difference was statistically insignificant ( $p>0.05$ ). Mean percent fertilization successes at 20,40, and 45 ppt were $3.5 \pm 1.1 \%, 15.9 \pm 9.0 \%$, and $43.0 \pm 0.4 \%$, respectively. Each of these treatments were significantly different from the control (Tukey, $\mathrm{p}<0.001$ ) but not significantly different from each other (Tukey, $\mathrm{p}>0.05$ ).

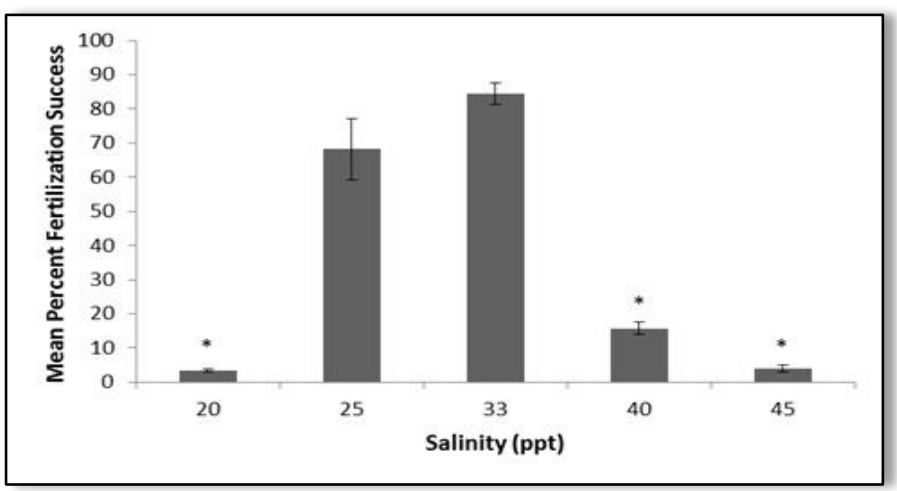

Figure 1. Fertilization success in E. parma decreases as salinity deviates from ambient levels. No significant difference in fertilization was observed among the 20, 40, and $45 \mathrm{ppt}$ treatments (Tukey, $p>0.05$ ). Asterisks indicate treatments significantly different from the control (33 ppt) (Tukey, $p<0.001$ ). Error bars represent standard error.

A negative trend was found in relation to presence of cleavage after fertilization and deviance from the control (Figure 2). The mean percent occurrence of cleavage in fertilized eggs was found to be $95.8 \pm 3.4 \%$ under control conditions. This value was not significantly different from those at 25 and $40 \mathrm{ppt}$, measured as $82.8 \pm 7.1 \%$ and $88.1 \pm$ $9.7 \%$, respectively (Tukey, $\mathrm{p}>0.05$ ). In these treatments, a delay in the appearance of cleavage was observed by approximately one hour. No cleavage was observed at $20 \mathrm{ppt}$ or 45 ppt (Tukey, $\mathrm{p}<0.001$ ).

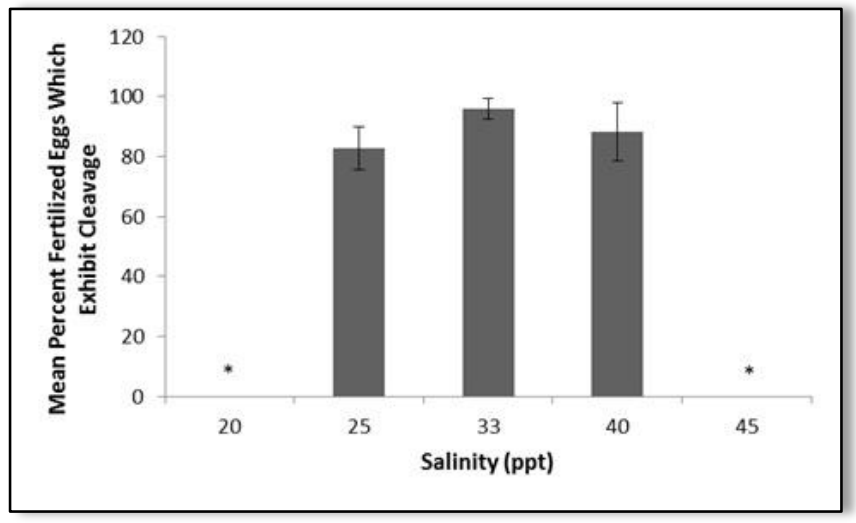

Figure 2. Occurrence of cleavage in fertilized eggs in E. parma was non-existent in the extreme salinities tested. No significant difference in mean percent of fertilized eggs that exhibit cleavage was found among the 25, 33, and 40 ppt treatment groups (Tukey, $p>0.05$ ). Asterisks indicate treatments significantly different from the control (Tukey, $p<0.001$ ). Error bars represent standard error.

It was observed that the majority of zygotes exposed to 20, 25, 33, 40, and 45 ppt demonstrated the developmental stages of: appearance of fertilization envelope, blastula, 


\section{Three short studies from field studies in marine biology and oceanography}

blastula, two-cell stage, and appearance of fertilization envelope, respectively (Figure 3). The vast majority of unfertilized eggs at 20, 40, and 45 ppt showed signs of damage; eggs treated in the hyposaline solution were found to have lysed, while those treated in the hypersaline solutions appeared to have shriveled and exhibited a bubble-like appearance (Figure 4).

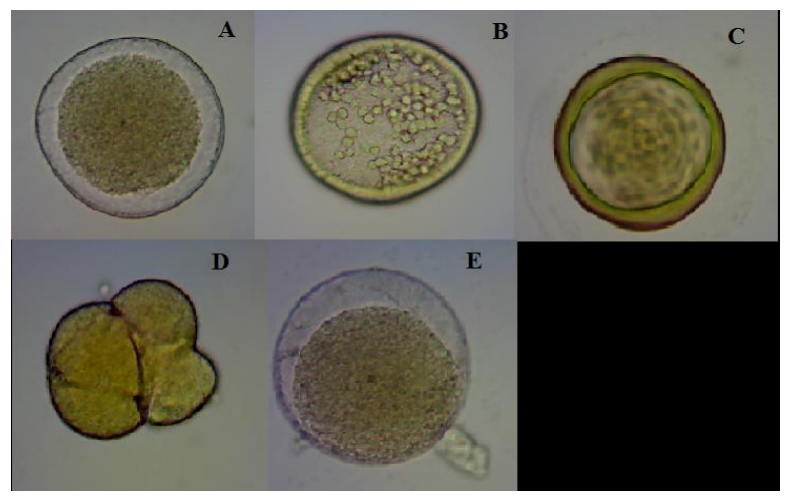

Figure 3. Furthest degree of development observed in each treatment after approximately 15 hours. A: $20 \mathrm{ppt}$, appearance of fertilization envelope; B: 25 ppt, blastula; C: 33 ppt, blastula; D: 40 ppt, late 2-cell stage; E: $45 \mathrm{ppt}$, appearance of fertilization envelope.

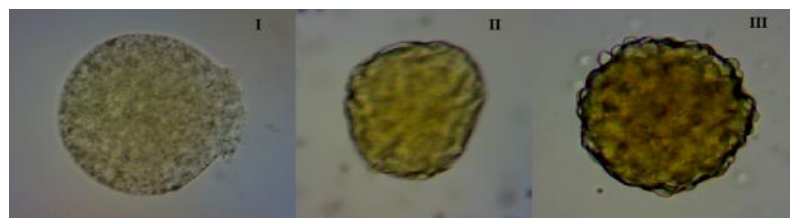

Figure 4. Damage caused to eggs in extreme salinity treatments. I: hyposaline, lysed; II: hypersaline, shriveled; III: hypersaline, bubble/blister-like appearance.

This study demonstrates that changes in salinity have detrimental effects on fertilization success and larval development of E. parma. As salinity levels deviated from the control, there was a decrease in fertilization success. There was also a decline in cleavage formation in fertilized eggs. Gametes subjected to extreme high and low salinities (45 and $20 \mathrm{ppt}$, respectively) showed no cleavage, while those incubated at 33 and 25 ppt survived to the blastula stage. Unfertilized eggs in the extreme salinities tested became damaged, those in hyposaline solution became lysed, and those in hypersaline solution became shriveled. This damage may have been the cause of the eggs' inability to become fertilized.

Typical echinoderm larval development consists of the two-cell stage occurring at approximately one hour postfertilization, followed by the 4-cell stage at one and a half to two hours, while the eight-cell stage occurs between two and three hours post-fertilization. The blastula stage is typically seen after five to eight hours (Williams \& Anderson, 1975; Vellutini \& Migotto, 2010). The current study found these results only in the control group. Similar results to this study were found by Bekova et al. (2004), who found that the sand dollar Scapechinus mirabilis is able to fertilize at salinities as low as 22 ppt, but larvae are unsuccessful in development as they do not survive past the blastula stage. This supports the findings of this study, suggesting that salinity plays a vital role in the reproductive success of E. parma.

It was found by Kashenko (2000) that the adult holothurian Eupentacta fraudatrix exhibits a lower salinity limit of $22 \mathrm{ppt}$, and embryogenesis was unable to be completed in salinities lower than 26 ppt. A later study by Kashenko (2003) regarding desalination tolerance in the sea stars Asterias amurensis and Patiria pectinifera found that adult organisms were unable to survive at salinities lower than 22 or $18 \mathrm{ppt}$, respectively. Locomotory ability was lost in $30-40 \%$ of $P$. pectinifera exposed to six or eight ppt for 21 or 28 hours, respectively. These findings offer further insight into the survivability of echinoderm species should oceanic salinities significantly fluctuate, and supports the notion that these species would be unsuccessful in maintaining population sizes in such an event.

A study involving the brittlestar Ophiothric fragilis by Dupont, Havenhand, Thorndyke, Peck, \& Thorndyke (2008) focused on the effects of increased oceanic $\mathrm{CO}_{2}$ levels on reproductive success with regards to global climate change. This study found that an increase in acidity by 0.2 units resulted in a $100 \%$ mortality rate among larvae over an eight day period. Abnormalities regarding size and skeletal proportions were also documented. These findings show that such $\mathrm{pH}$ fluctuations have the potential to eliminate this species. This also suggests that global climate change may affect species within benthic and pelagic ecosystems along with those in shallow estuarine waters.

It may be possible that E. parma along with other echinoderm species could evolve and adapt to the changing salinity levels to increase fertilization success. However, the data presented suggest this to be an unlikely event in the constrained time frame these changes would occur in due to the rapid nature of climate change and E. parma's environmental sensitivity (Meredith \& King, 2005; Harley et al., 2006; Przeslawski, Ahyong, Byrne, Woerheide, \& Hutchings, 2008).

Further studies investigating the adaptive capability of $E$. parma in a constrained time frame are encouraged for deeper insight into this issue. Continued studies that introduce adult organisms to various salinities before gamete collection may allow further insight into the effects of salinity on the reproductive success of E. parma. Damage to eggs was not quantified in a manner able to be represented through statistics; further studies concerning salinity's effect on echinoderm gametes should re-visit these findings and examine them further. Studies including other variables relating to global climate change such as $\mathrm{pH}$ and alkalinity concerning reproductive success in echinoderm species may offer further insight into the fate of this phylum regarding global climate change. 


\section{References}

Allen, J.D., \& Pechenik, J.A. (2010). Understanding the effects of low salinity on fertilization success and early development in the sand dollar Echinarachnius parma. The Biological Bulletin, 218, 189-199.

Bekova, N.V., Zhuravel, E.V., \& Khristoforva, N.K. (2004). Effects of delaniation and the detergent sodium dodecylsulphate on the early development of the sand dollar Scaphechinus mirabilis. Russian Journal of Marine Biology, $30,175-182$.

Binyon, J. (1966). Salinity tolerance and ionic regulation. In R.A. Boolotian (Ed.,), Physiology of Echinodermata. 359-377. New York, NY: Interscience.

Cattle, H., \& Crossley, J. (1995). Modelling arctic climate change. Philosophical Transactions of the Royal Society A, $352,201-213$.

Chen, X. (2012). A sensitivity analysis of low salinity habitats simulated by a hydrodynamic model in the manatee River estuary in Florida, USA. Estuarine, Coastal, and Shelf Science, 104, 80-90.

Dupont, S., Havenhand, J., Thorndyke, W., Peck, L., \& Thorndyke, M. (2008). Near-future level of $\mathrm{CO}_{2}$-driven ocean acidification radically affects larval survival and development in the brittlestar Ophiothrix fragilis. Marine Ecology Progress Series, 373, 285-294.

Geyer, W.R. (1997). Influence of wind on dynamics of flushing of shallow estuaries. Estuarine, Coastal, and Shelf Science, 44, 713-722.

Hanna, E., Huybrechts, P., Steffen, K., Cappelen, J., Huff, R., Shuman, C., Irvine-Fynne, T., Wise, S., \& Griffiths, M. (2008). Increased runoff from melt of the Greenland ice sheet: A response to global warming. Journal of Climate, 21, 331-341.

Harley, D.G., Hughes, A.R., Hultgren, K.M., Miner, B.G., Sorte, C.J.B., Thornber, C.S., Rodriguez, L.F., Tomanek, L., $\&$ Williams, S.L. (2006). The impacts of climate change in coastal marine systems. Ecology Letters, 9, 228-241.

Kashenko, S.D. (2000). Combined effect of temperature and salinity on the development of the holothurian Eupentacta fraudatrix. Russian Journal of Marine Biology, 26(3), 188-193.

Kashenko, S.D. (2003). The reaction of the starfish Asterias amurensis and Patiria pectinifera (Asteroidea) from Vostok Bay (Sea of Japan) to a salinity decrease. Russian Journal of Marine Biology, 29(2), 110-114.
Kashenko, S.D. (2006). The combined effect of temperature and salinity on development of the sea star Asteria Pectinifera. Russian Journal of Marine Biology, 32, 37-44.

Kashenko, S.D. (2007). Adaptive responses of embryos and larva of the heart-shaped urchin, Echinocardium cordatum to temperature and salinity changes. Russian Journal of Marine Biology, 33, 381-390.

Meredith, M.P. \& King, J.C. (2005). Rapid climate change in the ocean west of the Antarctic Peninsula during the second half of the $20^{\text {th }}$ century. Geophysical Research Letters, 32, L19604.

Myers, R.A., Akenhead, S.A., \& Drinkwater, K. (1990). The influence of Hudson Bay runoff and ice-melt on the salinity of the inner Newfoundland Shelf. Atmosphere-Ocean, 28(2), 241-256.

Przeslawski, R., Ahyong, S., Byrne, M., Woerheide, G., \& Hutchings, P. (2008). Beyong corals and fish: The effects of climate change on noncoral benthic invertebrates of tropical reefs. Global Change Biology, 14, 2773-2795.

Raper, S.C., \& Braithwaite, R.J. (2006). Low sea level rise projections from mountain glaciers and ice caps under global warming. Nature, 439(19), 311-313.

Rignot, E., \& Jacobs, S.S. Rapid bottom melting widespread near antarctic ice sheet grounding lines. Science, 296(5575), 2020-2023.

Tosuji, H., \& Sato, M. (2006). Salinity favourable for early development and gamete compatibility in two sympatric estuarine species of the genus Hediste (Polychaeta: Nereididae) in the Ariake Sea, Japan. Marine Biology, 3, 529-539.

Ushakova, O.O., \& Sarantchova, O.L. (2004). The influence of salinity on fertilizagtion and larval development of Neries virens (Polychaeta: Nereidae) from the White Sea. Journal of Experimental Marine Biology and Ecology, 301, 129-139.

Vellutini, B.C. \& Migotto, A.E. (2010). Embryonic, larval, and juvenile development of the sea biscuit Clypeaster subdepressus (Echinodermata: Clypeateroida). PLoS ONE, 5(3), e9654.

Williams, D.H.C. \& Anderson, D.T. (1975). The reproductive system, embryonic development, larval development and metamorphosis of the sea urchin Heliocidaris erythrogamma. Australian Journal of Zoology, 23, 371-403. 


\section{Effects of an autotomy event on the protein concentration of intact arms and respiration rate of Asterias vulgaris}

\section{Kaitlyn Wagner}

For correspondence please email: wagnerk@uoguelph.ca.

\section{Abstract}

Echinoderms are ecologically important organisms which are often caught as bycatch of trawl fisheries and undergo autotomy events to survive. Autotomy enables echinoderms to escape predators and trawl nets, but the physiological costs of this phenomenon are not well understood. This study investigated the immediate physiological impacts of such autotomy events on a common marine echinoderm, Asterias vulgaris. Protein content of adjacent intact arms and the metabolic rate of $\boldsymbol{A}$. vulgaris were compared immediately before and after an autotomy event. An induced autotomy event caused a significant decrease in protein content of intact arms and an unexpected significant decrease in metabolic rate. These results provide significant support for the energy allocation theory, where energy from intact arms is directed to the regeneration of a new arm, following autotomy. This response requires energy which would oth erwise be allocated to growth and reproduction, causing overall fitness of asteroids to decrease following autotomy events. Autotomized echinoderms may therefore escape predators and trawl nets; however, decreased fitness following such an event may disable the population from recovering quickly. This study adds to the growing body of literature demonstrating a need for strict regulations and reduced trawl fishing in benthic community hot spots.

Keywords: Asterias vulgaris; autotomy; physiological impact; protein content; metabolic rate; trawl fishing

\section{Introduction}

Trawl fisheries have detrimental effects on benthic communities, including altered community structure and damaged habitats (Kaiser, 1996; Ramsay, Kaiser, \& Richardson, 2001). They have an especially large impact on echinoderms, which often constitute the majority of bycatch organisms (Bergmann \& Moore, 2001). Most ophiuroids, crinoids, and asteroids caught as bycatch experience injuries to their arms and central disk and in severe cases, arms may be autotomized (Bergman \& Moore, 2001; Emson \& Wilkie, 1980). Autotomy is the voluntary dissociation of an appendage and is conventionally used as a survival strategy to escape predation attacks. This response has also become used to enable the escape from entanglement of trawl nets (Barrios, Gaymer, Vasquez, \& Brokordt, 2008; Maginnis, 2006; Ramsay et al., 2001). Autotomy facilitates survival, but there are costs in terms of growth and reproduction (Barrios et al., 2008; Fleming, Muller, \& Bateman, 2007; Lawrence, 2010). Autotomy has direct consequences on mobility and reproduction, which may decrease the fitness of an organism (Barrios et al., 2008).

Recent work has demonstrated that echinoderms that escape trawl nets by autotomizing an arm have an increased likelihood of survival (Diaz-Guisado, Gaymer, Brokordt, \& Lawrence, 2006). However, the specific physiological processes that enable the organism to heal from such trauma have not thoroughly been (Diaz-Guisado et al., 2006; Maginnis, 2006). It has been proposed that modifications of energy use and energy demand may allow the organism to cope with arm loss and begin regenerative processes (Pomory \& Lawrence, 1999). Previous studies have shown that energy stores of the remaining intact arms decreased following the autotomy of another limb (Diaz-Guisado et al., 2006). It has been suggested that these results provide evidence for energy reallocation (Barrios et al., 2008; Diaz-Guisado et al., 2006; Lares \& Lawrence, 1994; Ramsay et al., 2001). Furthermore, there is evidence of increased energy demands in autotomized brittle stars, as shown by an increase in respiration rate (Pomory \& Lawrence, 1999). As trawl fisheries continue to eradicate benthic communities, further examination of the physiological changes associated with survival strategies of many echinoderms such as autotomy is required.

The purpose of this study was to examine the immediate physiological changes induced by autotomy on Asterias vulgaris to gain insight into the effects of trawl fishing on benthic organisms. The A. vulgaris model was well suited to this investigation because asteroids have five arms with thick body walls encapsulating a large amount of gonads and pyloric caeca (Wollerman, Ferrier, Dyda, Brenner, \& Lindstrom, 2010; Lawrence, 2010). Thus, autotomy represents a greater loss of investment in asteroids, such as A. vulgaris, when compared to crinoids or ophiuroids (Lawrence, 2010). The protein content of pulverized pyloric caeca was measured. Protein is the main constituent of the organic matter of asteroid arms, and wound healing and regeneration following autotomy requires a significantly large quantity of protein to provide the necessary building blocks for fuel and tissue rebuilding (Lawrence, 2010). 
Metabolic rate was calculated because it is a useful indicator of energy demand by the whole organism (Pomory \& Lawrence, 1999).

By estimating the protein content of intact arms and overall metabolic rate before and after autotomy, this study examined the immediate physiological changes occurring in A. vulgaris after autotomy. Regeneration is facilitated by a redistribution of energy from the intact arms to regenerating arms. As a result, it was predicted that the protein concentration of the pyloric caeca of intact arms would decrease after autotomy. Moreover, given that autotomy is an energetically costly event to compensate for the loss of metabolically active tissue, the metabolic rate of the sea star was expected to increase after autotomy.

\section{Methods}

\section{Experimental procedure}

Twelve A. vulgaris were obtained from Passamaquoddy Bay in the Bay of Fundy, Canada. Specimens were transferred to the Huntsman Marine Science Centre in New Brunswick and were maintained in a 20 gallon holding tank containing aerated sea water of a standard temperature of approximately $14^{\circ} \mathrm{C}$. Specimens were fasted for 72 hours prior to experimentation.

To identify each specimen, the second arm to the right of the madreporite was pierced with a precision guide needle (18G $1 \frac{1}{2}$ 2 Becton Dickson \& Co.), threaded with plain

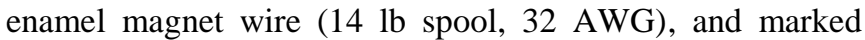
with a piece of numbered flagging tape one day before experimentation (1" x 200' Johnson \#3301-P). The magnet wire was wrapped around the arm and tied in a double knot to secure the flagging tape to the arm. Each specimen was then weighed using an Acculab scale (VI-400) and Vernier calipers were used to measure the length of the arm to be autotomized (the arm second to the left of the madreporite) from the tip of the arm to the beginning of the central disk.

The respiration rate of each specimen was measured with a Vernier Lab Pro 10 respirometer. The respirometer was calibrated with sodium sulfite calibration solution (Flinn Scientific Inc. 2M solution) and was operated by Logger Pro 3.7.4.2 (Vernier Software and Technology). The probe of the respirometer was inserted into a closed respirometry chamber with a stir bar which was placed upon a stir bar plate (ID\# 18180, Fisher Scientific) to prevent the water from becoming stagnant. Each specimen was acclimated to the respirometry chamber for ten minutes prior to experimentation. One $A$. vulgaris was then placed on their oral side in the closed respirometry chamber and dissolved oxygen levels were measured by the Vernier Lab Pro 10 respirometer until a declining trend was observed. The volume of water in the chamber was measured with a graduated cylinder, once the probe and the organism were removed. This procedure was repeated for each of the twelve specimens.
Two hours after initial respiration rates were measured, autotomy of the arm second to the left of the madreporite was induced with a pair of pliers. The pyloric caeca was then removed and chopped into fine pieces with a scalpel for ten seconds. The fine pieces were vortexed in a Fisher Scientific Touch Mixer (Model 231) for one minute and spun in an Allied Fisher Scientific micro-centrifuge (Model 235c) on high for two minutes. A micropipette was used to removed the supernatant and place it into a microcentrifuge tube. To determine the protein content in the pyloric caeca, a Bio-Rad protein microassay was used. A 1:4 ratio of Bio-Rad protein assay dye reagent concentrate (Cat\# 500-0006) diluted with distilled water was added to $50 \mu \mathrm{L}$ of each of the pyloric caeca samples. These solutions were then decanted into a cuvette and a Vernier Spectrometer (powered by Ocean Optics Inc.), operated by Logger pro 3.4.6. (Vernier Software and Technology), was used to measure the absorbance of each sample. A standard curve for the Bio-Rad Protein Assay was constructed to determine the protein content of each pyloric caeca sample from the measured absorbance.

Respiration rates were measured again at 48 hours after the initial autotomy event was induced because at this time wound healing was expected to be complete and true regeneration would have begun (Carnevali, Lucca, \& Bonasoro, 1993). A second autotomy event was induced on the arm left of the madreporite; pyloric caeca was removed and protein content was determined as mentioned above.

To determine the dry weight of the specimens, they were anaesthetized with $10 \mathrm{~g}$ of diluted tricaine methanesulfonate (Aldrich MS 222) for five minutes, and then placed in a Despatch drying oven, along with the autotomized arms. The specimens were weighed and then returned to the Despatch drying oven until the weight remained unchanged to ensure all water was evaporated. Each specimen was then weighed a final time to determine the dry weight of the entire organism to utilize for a calculation of metabolic rate.

\section{Statistical analysis}

A Student's paired t-test was used to determine if there was a significant difference between metabolic rates before and after autotomy events. Individual metabolic rates were calculated by multiplying the change in dissolved oxygen levels (i.e., the respiration rate) by the volume of the chamber, divided by the mass of the organism, multiplied by total time in the chamber. In addition, a second Student's paired t-test was used to determine if there was a significant change in protein content of the intact arms before and after autotomy events. 


\section{Results and Discussion}

A significant difference was observed between the protein content of the pyloric caeca of intact arms before and after autotomy ( $<<0.05$; Figure 1). The mean protein content of the pyloric caeca of intact arms before autotomy was $0.33 \pm 0.04 \mathrm{mg} \mathrm{mL}^{-1}$ whereas the protein content of intact arms after autotomy was $0.15 \pm 0.02 \mathrm{mg} \mathrm{mL}^{-1}$. As predicted, protein content of the pyloric caeca of intact arms decreased significantly following autotomy $(\mathrm{p}<0.05)$. This suggests that protein from intact arms was being allocated to the autotomized stump for wound healing and early regeneration processes. This provides significant support for the hypothesis that sea stars allocate energy from intact arms to autotomized arms following autotomy events.

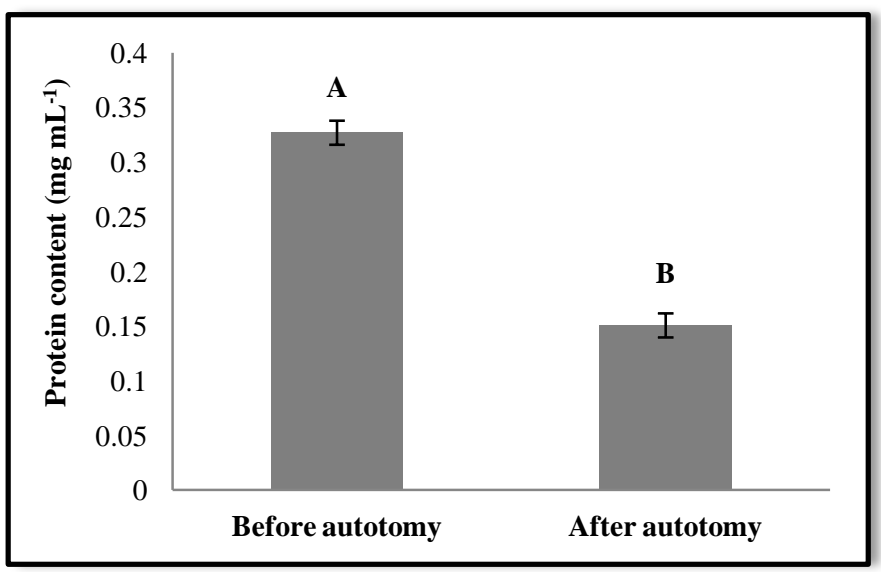

Figure 1. Average protein content of the pyloric caeca of intact arms of twelve $A$. vulgaris before autotomy and immediately after autotomy $(p<0.05)$. Standard errors of the mean are indicated by error bars. Letters A and B indicate a significant statistical difference in protein concentration before and after autotomy.

Furthermore, a significant difference was observed between the metabolic rate of A. vulgaris before and after autotomy events $(\mathrm{p}<0.05$; Figure 2). Mean metabolic rate before autotomy was $3.8 \times 10^{-3} \pm 0.38 \times 10^{-3} \mathrm{mg} \mathrm{mg}^{-1} \mathrm{~min}^{-1}$ whereas mean metabolic rate after autotomy was $1.3 \times 10^{-3} \pm 0.091 \times 10^{-3}\left(\mathrm{mg} \mathrm{O}_{2}\right)(\mathrm{mg} \text { animal })^{-1} \mathrm{~min}^{-1}$. Contrary to what was predicted, the metabolic rate of $A$. vulgaris significantly decreased following autotomy $(\mathrm{p}<0.05)$. The energy conservation strategies of starved specimens may have caused the unexpected decrease in metabolic rate (Clements, Stancyk, Lincoln, Dobson, \& Showman, 1993). Perhaps the animals in the current study did not have the energy reserves to support an increase in metabolic rate due to the autotomy event. Overall, the results of this study show that autotomy events have significant, immediate physiological consequences on A. vulgaris.

The results of the current study are consistent with findings from previous studies which found that autotomy decreased the protein content in the intact arms of various asteroids. A study by Diaz-Guisado et al. (2006) found that

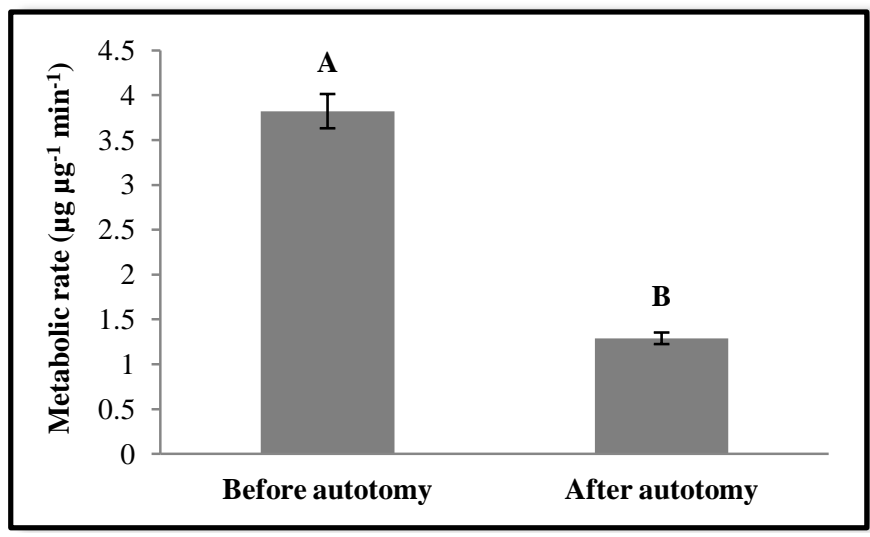

Figure 2. Average metabolic rate of twelve $A$. vulgaris two hours before autotomy and 48 hours after autotomy $(p<0.05)$. Standard errors of the mean are indicated by error bars. Letters $A$ and $B$ indicate a significant statistical difference in metabolic rate before and after autotomy.

after four months, an asteroid (Stichaster striatus) with two autotomized arms had five-fold lower protein content of pyloric caeca when compared to intact individuals. In addition, the results of a four week study indicated that the protein content of the pyloric caeca of the asteroid Heliaster helianthus with five to ten autotomized arms was five to six times less than in intact individuals (Barrios et al., 2008). The results of these studies are accordingly comparable because $H$. helianthus can develop a total of forty arms; thus, the autotomy of five to ten arms in H. Helianthus is relative to the autotomy of two arms in A. vulgaris or S. striatus (Barrios et al., 2008). Similar to the current study, it was concluded that the significant decrease in protein content of intact arms following autotomy indicated impaired growth and decreased capacity for energy storage, thereby decreasing the overall fitness of each individual (Diaz-Guisado et al., 2006; Barrios et al., 2008).

The results of the current study contrast findings from previous studies regarding respiration rate and protein content in the arms of ophiuroids following autotomy. Pomory and Lawrence (1999) examined and compared the biochemical components of the disk, intact arms and stomach and respiration rates of intact and autotomized blunt-spined brittle stars (Ophiocoma echinata). They did not find a significant difference of organic matter or lipid or protein content between the two groups; however, they did find a significantly higher respiration rate in autotomized O. echinata after 8 days (Pomory \& Lawrence, 1999). Unlike the arms of deposit and/or suspension feeding ophiuroids, the arms of predatory asteroids have thick body walls encapsulating a large amount of gonads and pyloric caeca (Wollerman et al., 2010; Lawrence, 2010). Therefore, A. vulgaris should have a greater loss of investment represented by a significant loss of protein. Moreover, it is likely that an increase in respiration rate was not observed in the current study because unlike specimens from the study by Pomory and Lawrence (1999), the specimens in the current study 
were starved and the study duration was relatively short.

A limitation of determining the physiological impact of autotomy on echinoderms is defining the time at which physiological changes are attributable to regeneration, rather than wound healing. An autotomy event involves the breakage of the pyloric duct and body wall, and mass amounts of cellular movement and re-epithelization are required to close the wound in preparation for regeneration (Carnevali et al., 1993; Wilkie, 2001). There is evidence that the completion of these wound healing processes requires up to 24 hours in crinoids and 20 days in ophiuroids, and that it is only after this time interval that true regenerative processes such as cell growth and differentiation can occur (Pomory \& Lawrence, 1999; Carnevali et al., 1993). Future studies should measure physiological responses to autotomy in asteroids for longer than the 48 hour duration of the current study to determine if fitness is decreased during true regenerative processes.

A post-autotomy trend was observed in regards to the arrangement of the remaining arms around the circumference of the central disk after autotomy. The radial symmetry of intact pentaramous $A$. vulgaris creates a stable body configuration that is destroyed after an autotomy event (Hotchkiss, 1979). Thus, the organism must regain a stable post-autotomy body configuration. In the current study, less than 48 hours after one arm was autotomized, the remaining arms were evenly repositioned around the central disk so that the organism assumed the shape of an " $\mathrm{X}$ ". Furthermore, less than 48 hours after two arms were autotomized, the remaining arms were once again evenly repositioned around the central disk so that the organism assumed a triradiate shape. It is speculated that the redistribution of arms around the central disk may increase the survivorship of vulnerable autotomized individuals by enabling the organism to reach a stronger, more stable body configuration. For example, the tetrameric and triradiate body shapes may allow the organism to better withstand tension or other mechanical stressors, such as wave action or predators, which have an increased likelihood of dislodging the organism during its vulnerable state. These observations may have implications for the biomechanical and physiological consequences of autotomy events and therefore warrant further investigation.

This study provides further insight into the immediately severe physiological impacts of autotomy events on echinoderms. The findings show that the fitness of autotomized asteroids is immediately and significantly reduced. While autotomized echinoderms may escape predators and trawl nets, decreased fitness following such an event may disable the population from recovering quickly. It is apparent that stringent regulations on trawl fishing are required to conserve benthic community hot spots.

\section{References}

Barrios, J.V., Gaymer, C.F., Vasquez, J.A., \& Brokordt, K.B. (2008). Effect of the degree of autotomy on feeding, growth, and reproductive capacity in the multi-armed sea star Heliaster helianthus. Journal of Experimental Marine Biology and Ecology, 361, 21-27.

Bergmann, M., \& Moore, P.G. (2001). Mortality of Asterias rubens and Ophiura ophiuroidea discarded in the Nephrops fishery of the Clyde Sea area, Scotland. ICES Journal of Marine Science, 58, 531-542.

Carnevali, D.C., Lucca, E., \& Bonasoro, F. (1993). Mechanisms of arm regeneration in the feather star Antedon mediterranea: Healing of wound and early stages of development. Journal of Experimental Zoology, 267, 299-317.

Clements, L.A.J., Stancyk, S.E., Lincoln, D.E., Dobson, W.E., \& Showman, R.M. (1993). Uptake of free amino acids by the ophiuroids Microphiopholis gracillima (stimpson) (Echinodermata) during disc regeneration. Comparative Biochemistry and Physiology, 105(A), 793-802.

Diaz-Guisado, D., Gaymer, C.F., Brokordt, K.B., \& Lawrence, J.M. (2006). Autotomy reduces feeding, energy storage and growth of the sea star Stichaster striatus. Journal of Experimental Biology and Ecology, 338, 73-80.

Emson, R.H., \& Wilkie, I.C. (1980). Fission and autotomy in echinoderms. Oceanography and Marine Biology: An Annual Review, 28, 155-250.

Fleming, A., Muller, D., \& Bateman, P.W. (2007). Leave it all behind: A taxonomic perspective of autotomy in invertebrates. Biological Reviews, 82, 481-510.

Hotchkiss, H.C. (1979). Case studies in the teratology of starfish. Proceedings of the Academy of Natural Sciences of Philadelphia, 131, 139-157.

Kaiser, M.J. (1996). Starfish damage as an indicator of trawling intensity. Marine Ecology Progress Series, 134, 303-307.

Lares, M.T., \& Lawrence, J.M. (1994). Nutrient and energy allocation during arm regeneration in Echinaster paucispinus (Clark) (Echinodermata; Asteroidea). Journal of Experimental Marine Biology and Ecology, 180, 49-58. 
Lawrence, J.M. (2010). Energetic costs of loss and regeneration of arms in stellate echinoderms. Integrative Comparative Biology, 50, 506-514.

Maginnis, T.L. (2006). The costs of autotomy and regeneration in animals: a review and framework for future research. Behavioral Ecology, 17, 857-872.

Pomory, C.M., \& Lawrence, J.M. (1999). Effect of arm regeneration on energy storage and gonad production in Ophiocoma echinata (Echinodermata: Ophiuroidea). Marine Biology, 135, 57-63.
Ramsay, K., Kaiser, M.J., \& Richardson, C.A. (2001). Invest in arms: Behavioral and energetic implications of multiple autotomy in starfish (Asterias rubens). Behavioral Ecology and Sociology, 50, 360-365.

Wilkie, I.C. (2001). Autotomy as a prelude to regeneration in echinoderms. Microscopy Research Technique, 55, 369-396.

Wollerman, L., Ferrier, M.D., Dyda, R., Brenner, J., \& Lindstrom, D. (2010). Activity pattern of the brittlestar Ophiocoma echinata (Echinodermata: Ophiuroidea) and its relationship to foraging and predation potential. Occasional Publications of the Society for Ocean Science, 1, 1-6. 